\title{
Body-Centric Wireless Communications: A Survey of Hearing-Instrument Antennas
}

\author{
Jakobsen, Kaj Bjarne
}

Published in:

Proceedings of IEEE Radio and Antenna Days of the Indian Ocean

Link to article, DOI:

10.23919/RADIO.2018.8572372

Publication date:

2018

Document Version

Peer reviewed version

Link back to DTU Orbit

Citation (APA):

Jakobsen, K. B. (2018). Body-Centric Wireless Communications: A Survey of Hearing-Instrument Antennas. In Proceedings of IEEE Radio and Antenna Days of the Indian Ocean IEEE.

https://doi.org/10.23919/RADIO.2018.8572372

\section{General rights}

Copyright and moral rights for the publications made accessible in the public portal are retained by the authors and/or other copyright owners and it is a condition of accessing publications that users recognise and abide by the legal requirements associated with these rights.

- Users may download and print one copy of any publication from the public portal for the purpose of private study or research.

- You may not further distribute the material or use it for any profit-making activity or commercial gain

- You may freely distribute the URL identifying the publication in the public portal

If you believe that this document breaches copyright please contact us providing details, and we will remove access to the work immediately and investigate your claim. 


\title{
Body-Centric Wireless Communications: A Survey of Hearing-Instrument Antennas
}

\author{
Kaj B. Jakobsen \\ Department of Electrical Engineering, Electromagnetic Systems, Technical University of Denmark, \\ Ørsteds Plads, Building 348, DK-2800 Kgs. Lyngby, Denmark \\ kbj@elektro.dtu.dk
}

\begin{abstract}
A survey of hearing-instrument antennas used for body-centric wireless communications is presented. One challenge is to transmit a radio signal from a hearing instrument on one ear to a hearing instrument on the other ear to improve the hearing quality. Transmission through the head is not an option due to the losses at the ISM-band at $2.4 \mathrm{GHz}$. This is overcome by the use of surface waves, i.e., a wave that creeps on the top of the head. A major challenge is to construct antennas that effective launches surface waves for different types of hearing instruments.
\end{abstract}

\section{INTRODUCTION}

Body-centric wireless communications have received much attention in the literature in recent years. This is due to the rise of small body-worn devices, which need to communicate wirelessly in order to offer improved functionality to the user. The Industrial, Scientific and Medical (ISM) band at $2.4 \mathrm{GHz}$ is license free worldwide, and is therefore used to enable many Wireless Body Area Network (WBAN) applications. Additionally, all modern mobile phones are already equipped to communicate at $2.4 \mathrm{GHz}$ by the use of the widespread Bluetooth ${ }^{\circledR}$ protocol.

Hearing Instruments (HIs) are a good example of such small body-worn devices that have become increasingly advanced in recent years. Modern top-line HIs are thus expected to be able to communicate wirelessly with mobile accessories, such as audio streamers and mobile phones. Furthermore, the binaurally fitted HIs are needed to communicate wirelessly with each other, ear-to-ear, in order to synchronize the amplification settings between the HIs. Further, it is possible to obtain audiological advantages, which, e.g. eases conversation in noisy areas. In order to conserve power, the accessorylink and the ear-to-ear link need to utilize the same radio and antenna. The challenge in using $2.4 \mathrm{GHz}$ is that the head is lossy at these frequencies, with a skin depth $\delta_{\mathrm{s}} \approx 21 \mathrm{~mm}$. Therefore, the energy cannot propagate through the head. Instead the energy propagates around the head as creeping waves [1], [2].

In this presentation, the characteristics of the ear-to-ear onbody propagation will be surveyed. Additionally, some of the many examples of $\mathrm{HI}$ antennas found in the literature will be reviewed, e.g., [3]-[6], which are antennas that are suitable for use in small ear-worn devices.

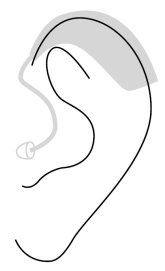

(a)

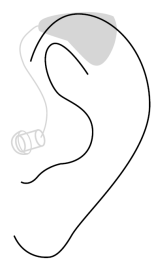

(b)

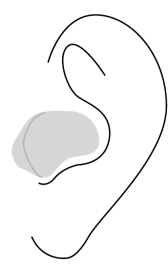

(c)

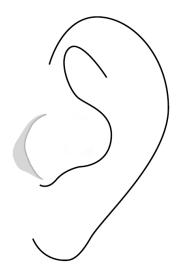

(d)
Fig. 1. The hearing instrument (HI) types in the use position for Behindthe-Ear (BTE) (a), Receiver-in-the-Ear (RIE) (b), In-the-Ear (ITE) (c), and the smaller versions of the ITE, the In-the-Canal (ITC) and Completely-inthe-Canal (CIC) (d) [1].

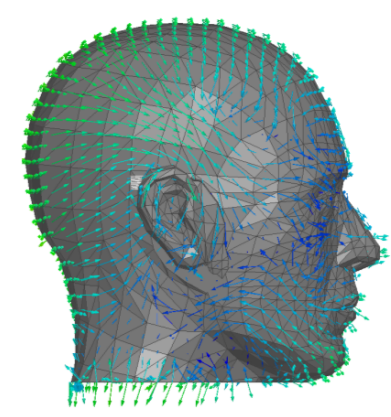

(a)

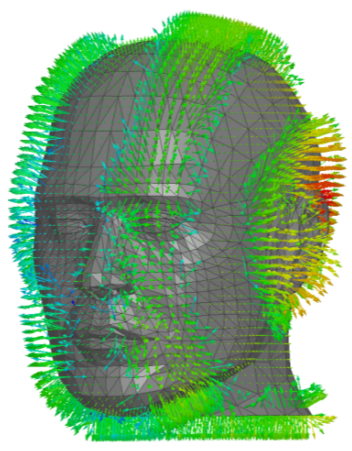

(b)
Fig. 2. Simulated Poynting vector (a) and electric field vectors (b) on the SAM head with ears [7]-[9].

\section{HeARING-INSTRUMEnT TyPeS}

The HIs can be classified in four main types, see Fig. 1. The Behind-The-Ear (BTE) and the Receiver-In-the-Ear (RIE) HIs sit behind the ear, as shown in Fig. 1a and Fig. 1b, respectively. The In-The-Ear (ITE) and In-The-Canal (ITC) types are custom-made to fit the individual ear canals, and are shown in Fig. 1c and Fig. 1d, respectively. Common to all four types is that they are generally made as small as possible, in an effort to conceal the devices.

\section{CReeping WAVES}

To improve hearing radio signals are transmitted from the antenna in the hearing instrument on one ear to the antenna in the hearing instrument on the other ear. Transmission of the signal through the head is not an option due to the very high losses at the ISM-band at $2.4 \mathrm{GHz}$. This is overcome by the 


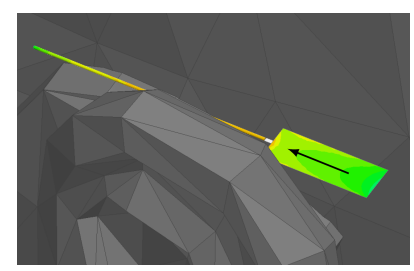

(a)

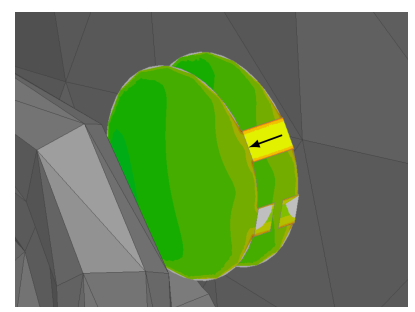

(c)

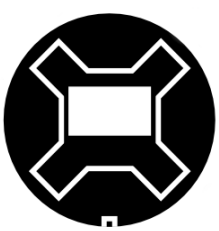

(e)

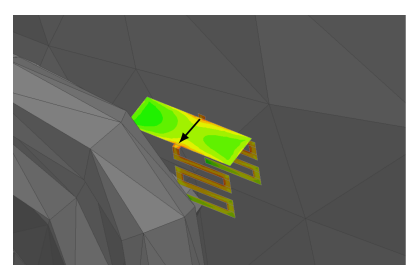

(b)

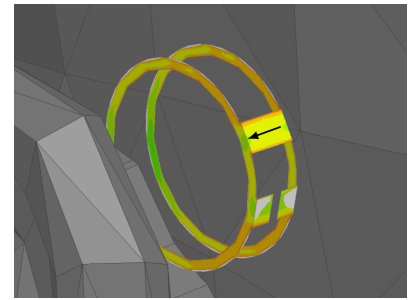

(d)

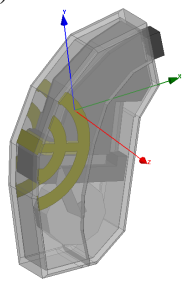

(g)
Fig. 3. Hearing-Instrument antenna types shown with simulated surface current distributions. A straight monopole antenna that rests on top of the ear (a), a meandered monopole antenna that is fed at the center of the side of the ground plane (b), antenna with two parallel circular plates (c) and rings (d) [1], [11], a meandered slot antenna (e) [12], a custom shell antenna (f) [13], and an electric coupled antenna [6].

use of creeping waves that propagates on the surface of the head. To do this the challenge is to construct antennas that effectively launches creeping waves, e.g., the electric field is perpendicular to the surface. Optimal antenna are developed for each type of hearing instrument. Typical measured propagation losses are in the range 50-80 dB depending on the type of hearing instrument. Simulations of the creeping waves at the surface of the head on a specific anthropomorphic mannequin (SAM) head of the electric field vectors and Poynting vector are shown in Fig. 2.

\section{HEARING-INSTRUMENT ANTENNAS}

To obtain a low path loss, i.e., high on-body path gain $\left(\left|S_{21}\right|\right)$ the on-body antenna is oriented such that the electric field is perpendicular to the surface of the head. This will ensure an efficient launch of a creeping wave [1]. Further, the antenna should radiate along the surface of the body. Many hearing-instrument antennas have been presented in the literature, e.g., [6], [7], [10]-[13]. However, to be useful, e.g., in HIs, the antenna must be physically small in order to fit the devices-but not necessarily electrically small at $2.4 \mathrm{GHz}$. Typical measured fractional bandwidths are in the range 1-10\%. Examples of hearing-instrument antennas for body-centric wireless communications are shown in Fig. 3.

\section{CONCLUSION}

The main types (BTE, RIE, ITE, and CIC) of hearing instruments have been introduced. The different hearing-instrument antenna types used for body-centric wireless communications at the $2.4 \mathrm{GHz}$ ISM band are presented. The ear-to-ear propagation communication relies on creeping waves on the surface of the head.

\section{REFERENCES}

[1] S. H. Kvist, Antennas and Propagation for Body-Centric Wireless Communications. Ph.D. dissertation, DTU Elektro, Technical University of Denmark (DTU), Kgs. Lyngby, Denmark, ISBN 978-87-92465-47-4 2013.

[2] S. H. Kvist, J. Thaysen, and K. B. Jakobsen, "Polarization of unbalanced antennas for ear-to-ear on-body communications at $2.45 \mathrm{GHz}$," Loughborough Antennas \& Propagation Conference, pp. 1-4, 2011, First Prize for the IET Best Student Paper 2011 Loughborough Antennas and Propagation Conference (LAPC), November 2011.

[3] S. Pehrson, S. H. Kvist, K. B. Jakobsen, and J. Thaysen, "Morphological investigation of the differences on the ear-to-ear path gain and the packet loss at $2.45 \mathrm{GHz}$, ' 34th Annual Antenna Measurement Techniques Association Symposium 2012, pp. 43-48, 2012.

[4] S. H. Kvist and K. B. Jakobsen, "Investigation of the chest-ear radio propagation channel," EuCAP 2010 - the 4th European Conference on Antennas and Propagation, p. 5505460, 2010.

[5] N. P. I. Kammersgaard, S. H. Kvist, J. Thaysen, and K. B. Jakobsen, Body-Worn Spiral Monopole Antenna for Body-Centric Communications. IEEE, 2015, pp. 107-110, Best Student Paper Award at the "International Workshop on Antenna Technology" (iWAT) held in Seoul, South Korea.

[6] L. Færch, S. H. Kvist, J. Thaysen, and K. B. Jakobsen, ElectricCoupled Antenna for Hearing-Instrument Applications. IEEE, 2016, Best Student Paper nominee at 2016 Loughborough Antennas and Propagation Conference (LAPC), 14 - 15 November 2016.

[7] S. H. Kvist, S. Özden, J. Thaysen, and K. B. Jakobsen, "Improvement of the ear-to-ear path gain at $2.45 \mathrm{GHz}$ using parasitic antenna element," 2012 6th European Conference on Antennas and Propagation, pp. 944 947, 2012.

[8] S. H. Kvist, J. Thaysen, and K. B. Jakobsen, "Investigation of the earto-ear radio propagation channel," in European Conference on Antennas and Propagation, 2011, pp. 3796-3800.

[9] S. Kvist, J. Thaysen, and K. B. Jakobsen, "The effect of the head size on the ear-to-ear radio-propagation channel for body-centric wireless networks," in Loughborough Antennas \& Propagation Conference, 2010, pp. $345-348$

[10] S. H. Kvist, K. B. Jakobsen, and J. Thaysen, "Design and measurement of a $2.45 \mathrm{GHz}$ on-body antenna optimized for hearing instrument applications," 34th Annual Antenna Measurement Techniques Association Symposium 2012, pp. 33-37, 2012

[11] N. P. I. Kammersgaard, S. H. Kvist, J. Thaysen, and K. B. Jakobsen, "Inthe-ear spiral monopole antenna for hearing instruments," Electronics Letters, vol. 50, no. 21, 2014.

[12] W. H. Yatman, L. K. Larsen, S. H. Kvist, J. Thaysen, and K. B. Jakobsen, "In-the-ear hearing-instrument antenna for ISM-band body-centric earto-ear communications," LAPC 2012 - 2012 Loughborough Antennas and Propagation Conference, pp. 1-4, 2012.

[13] A. Ruaro, J. Thaysen, and K. B. Jakobsen, "Wearable shell antenna for $2.4 \mathrm{GHz}$ hearing instruments," IEEE Transactions on Antennas and Propagation, vol. 64, no. 6, pp. 1-9, Jun. 2016. 